\title{
When Traditional Ethnic Culture Encounters Gender Equality: The Dilemma Of Multicultural Education
}

\author{
Shan-Hua Chen, National Chiayi University, Taiwan
}

\begin{abstract}
In recent years, the government of Taiwan has been actively promoting gender equality, the positive results of which are already apparent among the younger generation. This research examines the views of indigenous girls attending secondary school with respect to the gender divide in their traditional culture, whether or not they support the concept of gender equality, and how their career plans are associated with their gender perceptions. Data were collected through participant observation and group interviews. The results indicate that female aboriginals of higher socio-economic standing are becoming less constrained by traditional gender limitations. Although their traditional culture may run counter to the ideology of gender equality, in reality many are learning how to draw on the wisdom of their traditional culture without adopting the concept of masculine domination.
\end{abstract}

Keywords: Gender Equality; Taiwan Aboriginals; Traditional Culture

\section{INTRODUCTION}

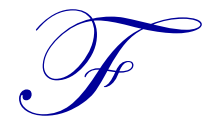

patriarchal.

Although the concept of gender equality has been widely accepted among the younger generation-both Han Chinese and aboriginals - it can't be denied that many of Taiwan's indigenous cultures stress gender divisions within the workplace and give men the leading role in various traditional festivals and rituals. Such patriarchal traditions stand in sharp contrast to the ideals of gender equality.

This research thus endeavors to explore the views of indigenous girls attending secondary school with respect to the gender divide in their traditional culture, whether or not they support the concept of gender equality, and how their career plans are associated with their gender perceptions. Participant observation and interviews with 11 students were carried out at a private senior high school for girls between September 2010 and December 2011.

\section{REVIEW OF THE RELATED LITERATURE}

\section{Multicultural Education and Indigenous Students}

One of the goals of the civil rights movement in the United States is to remove racial discrimination from education. As part of this movement, multicultural education has, as one of its goals, the elimination of racism, sexism, and classism in schools (Sleeter\& Grant, 1987). Beginning in the 1960s, the government, non-government organizations, and communities in the U.S. began to seek ways to preserve and promote indigenous values, practices, languages, and knowledge (Arenas, Reyes, \& Wyman, 2010). A similar movement began in Taiwan a few decades later and the government has recently begun to promote multicultural education in schools, with a special focus on the traditional knowledge of indigenous people. 
The 14 different tribes officially recognized by the government constitute around two percent of the population, with the remainder of Taiwan's population consisting mainly of Han Chinese. While each tribe has its own culture and native language (all belonging to the Austronesian language family), over the course of several centuries, sinicization has resulted in the disappearance of many customs and languages. However, despite their high degree of assimilation to mainstream Chinese culture, numerous studies have shown that aboriginals are still very much at the bottom of Taiwan's socio-economic structure. Moreover, indigenous students tend to be less successful in the public school system (Yen, 2009; Wu, 2012).

Thus, aboriginal students in Taiwan face a variety of cultural, social, and educational challenges. Such marginalization is a common issue among indigenous students in many parts of the world, such as the aboriginal and islander communities in Australia (Warren, Cooper, and Baturo, 2009).

Redressing the disadvantaged status of indigenous students requires reducing the cultural differences between indigenous and non-indigenous groups, because students learn best when the learning is taking place in a familiar environment. Therefore, one way of enhancing the academic achievement of indigenous students is to integrate indigenous knowledge, innovations, and practices into the curriculum (Dei, 2010).

\section{Gender Equality}

In most societies, gender provides a framework for how individuals are expected to behave (Raffaelli \& Ontai, 2004). Children are taught by adults to behave according to the gender stereotypes current in a given society (Hong, 2004). Moreover, an individual's background factors (gender, academic achievement, etc.) tend to determine what gender stereotypes he or she holds. Since gender stereotypes may result in unequal treatment, it is important to develop effective strategies for promoting gender-equality in schools, families, and society, especially in places where gender stereotypes are deeply rooted, so that individuals can become free from culturally imposed conceptions of masculinity and femininity (Hong, Veach, \& Lawrenz, 2003).

Women especially suffer from discrimination in undeveloped or developing areas or countries, as well as in such places where gender stereotypes are deeply rooted it crucial to promote gender equality and the empowerment of women as a basic human right. It has been argued that eliminating gender stereotypes in economically disadvantaged areas will improve the overall level of education, which in turn will help to reduce such serious problems as poverty, hunger, and disease (Geo-JaJa, Payne, Hallam, \& Baum, 2009). It has also been argued that reducing gender inequality is an effective way of alleviating poverty and improving the health and education of the general public (Aslanbeigui, Pressman, \& Summerfield, 2003). Moreover, gender equality should be seen as a basic human right, and no one should be treated as inferior.

Social movements are the key to enhancing gender equality. Both the indigenous rights movement and the feminist movement assert that all individuals have the same fundamental human rights. However, as Richards (2005) has pointed out, whereas the indigenous rights movement emphasizes self-government, local control of natural resources, and the protection of traditional religions and languages, the focus of the gender rights movement and feminism is on gender equality.

\section{METHODOLOGY}

In carrying out this qualitative study, data were collected by using participant observation and group interviews with 11 female secondary school students from the Tsou tribe.

\section{Participants}

All of the participants were students at the Tanivu Girls School - a private high school in Chiayi City. Most of the parents of the participants were employed in public service or had stable work in the tribe; around one-third of the parents had completed a college degree and reside in one of the two main settlements of the Tsou tribe. Thus, in comparison to other aboriginals, the participants have a relatively high socio-economic status. The number and distribution of the participants is set out in Table 1: 
Table 1: The Number And Distribution Of The Participants

\begin{tabular}{|l|c|}
\hline \multicolumn{1}{|c|}{ Tribal Grouping } & Number of Participants \\
\hline Dabang Tribe & 3 \\
\hline Saviki Tribe & 3 \\
\hline Niahosa Tribe & 1 \\
\hline Tefuye Tribe & 3 \\
\hline Pnguu Tribe & 1 \\
\hline Total & 11 \\
\hline
\end{tabular}

\section{Observation}

The participant observation consisted of the tribe's traditional festivals and an evening-study program. The main festivals of the Tsou are Homeyaya, Mayasvi, and Fo'na. While taking part in these cultural activities, the activities of the indigenous youths were observed, especially the female secondary school students.

The observation of the evening study program focused on peer interactions, Tsou language training, and various cultural practices. Based on these observations, a semi-structured questionnaire was designed for use in the group interviews.

\section{Group interviews}

Based on the participant observations, descriptive questions were developed to elicit the students' opinions on gender issues. Using Spradely's (1979; 1980) methodology, the data were processed using domain analysis, taxonomic analysis, componential analysis, and cultural themes. The validity of the results was improved through the use of repeated self-reflection.

\section{FINDINGS}

Following are the key findings of the interviews.

\section{Education and Division of Labor}

Most of the participants' have mothers who are employed and also perform most of the housework. While the fathers are responsible for tribal activities, the mothers play an important role in their children's education. Most of the participants' families own tribal land and both sons and daughters are expected to assist with the farm work.

Overall, the participants' families have stable economic resources and give much emphasis to their children's education - both boys and girls - so that they won't fall behind their non-indigenous counterparts. In the senior high school stage, they send their children to study at relatively expensive private schools which offer higher quality education.

Interviewer: What are your parents' attitudes about your schoolwork?

Student 1: $\quad$ They kept an eye on my schoolwork during elementary school and junior high and always forced us to do our homework.

Student 2: $\quad$ My mom did that too. They paid more attention when I was in junior high.

Student 1: $\quad$ She said that we have to keep up with the non-indigenous students.

\section{Traditional Tribal Culture}

Although hunting is no longer an economic necessity, it remains an important part of the cultural heritage of many of Taiwan's indigenous peoples, and hunting expeditions are seen as a way of passing on tribe's traditional 
wisdom. However, hunting is generally limited to males, and several of the boys went hunting very often (Chen, 2009). In common with Taiwan's other aboriginal tribes, the elders of the Tsou tribe pass on to the younger generation the tribe's taboos and legends, as well as a wide range of related knowledge, including folk medicine and information about the local plants and animals in the course of which the young people also learn at least some of the tribal language.

Interviewer: Can you say more about how your father would use your tribal language to communicate with you when hunting?

Student 3: $\quad$ Once I got hurt and started bleeding. My father told me to find a certain plant, bite it, and apply the juice to the wound. When my dad sees animals, he uses our tribal language to talk about them. My dad taught me how to spot animals; he pointed out the animals to me and taught me how to use a shotgun.

Some of the hunting grounds are far away from the village and it can take two or three days of arduous walking to reach them. During such long hunting expeditions, the young men of the tribe learn to recognize animals, plants, and the key topographical features of their hunting grounds (Chen, Yang, Ho, and Wang, 2012). This is one of the chief ways in which young men imbibe the spirit of the Tsou tribe.

Some of the participants stated that they had asked their father to take them hunting, but they were always rejected. However, a few girls reported that they had gone hunting before. Moreover, a huntress has recently appeared in the tribe; she has hunted for wild boar by herself - something even the men find difficult.

\section{Traditional Rituals and Ceremonies}

The main rituals and ceremonies of Tsou tribe are all held in the two main communities - (hosa) of Tefuye and Dabang. Each of these villages has a men's house $(k u b a)$ which serves as the center of religion and administrative affairs, as well as an important tribal symbol.

Each ceremony includes certain taboos and also requires various preparations, such as brewing alcohol and cleaning ritual containers. In these traditional ceremonies, men play the leading role and the participation of women is largely limited to helping with the preparations.

Most students have never taken part in these ceremonies because they don't live in the two main villages. However, young males and, to a lesser extent, females who live in the two hosa do have some opportunities to participate in the tribal ceremonies and learn the traditional songs which accompany the rituals. However, since all the senior high students study in distant places, they are often unable to return for the ceremonies. A student stated, "In the past, Mayasvi was held to celebrate triumph in battle. Presently, it is held in certain months."

Student 4: $\quad$ We live in a paternalistic society, but it's not so bad.

Interviewer: What is your opinion about men playing the leading role in rituals?

Student 4: $\quad$ That's not true. We just follow the traditions. It's not bad.

\section{Female Students' Career Aspirations and Ethnic Identity}

Upon reaching the tenth grade, students in Taiwan are divided into two tracks - the natural sciences and the humanities tracks. Chen et al. (2012) found that all the male aboriginal students in one high school chose the humanities track and that their career inspirations are to become police officers, counselors, members of the clergy, or teachers. They all looked forward to making some contribution to the tribe in the future.

Among the 11 participants, five girls wanted to choose the natural science track, which is unusual since most girls choose the humanities track. Their career aspirations are to become public servants and medical personnel, 
hoping to improve the serious health problems of their tribe. Moreover, since the mountains of Taiwan are often struck by natural disasters, one of the girls wanted to engage in civil engineering:

Student 5: $\quad$ Because of the natural disasters here, I want to study civil engineering. . . The village headman told me that civil engineering would help the tribe. I can work in the mountains, so my parents also support this idea.

Even though some of the participants mentioned that their parents have encouraged them to go outside of the tribe to earn money and gain some life experience, most stated that after the completion of their studies, they want to return home to make some contribution to the tribe.

\section{CONCLUSIONS}

Because the parents of the participants in this study have stable jobs and income, they pay much attention to their children's education and generally agree with the idea of gender equity. Thus, they have high expectations for all their children, regardless of gender.

Because the hunting activities and traditional ceremonies of tribe are male-dominated, male students have more opportunity to participate in these important cultural activities. Although the tribe's traditional cultural activities continue to be male-dominated, young women don't tend to see this as a big problem, especially since such ceremonies don't play a major role in their daily lives. As for hunting, however, some change in traditional gender roles seems to be taking place, as evidenced by the participants' admiration of the female boar hunter.

The participants can thus be seen as stepping away from traditional gender limitations in schooling and employment, as demonstrated by the way in which many of them have chosen the science academic track as a way of making a contribution to their tribe.

For the aboriginal students, the tribe's cultural activities are not only a ceremony, but also a place for receiving traditional knowledge and cultivating a sense of identity. Although many of these activities are male dominated, gender equality is widely accepted in daily life.

Multicultural education helps indigenous students build their self-confidence through the revival of their traditional culture. Although some aspects of their traditional culture may go against the ideology of gender equality, in reality, indigenous students are making an adjustment to their traditional culture; they inherit the essence of their tribe's traditional wisdom, but not the concept of masculine domination.

\section{AUTHOR INFORMATION}

Shan-Hua Chen is an associate professor of GIEAPD(Graduate Institute of Educational Administration and Policy Development), National Chiayi University in Taiwan, who teaches courses in Sociology of Education, Multicultural Education, Methods and Materials for Social Studies Teaching in Elementary School, and Qualitative Research. While her early research addressed the education of the working-class students in Taiwan, her current research interests are highly related with indigenous education. She is non-indigenous, but devoted herself in indigenous education and research for years. She has published several research papers on selected journals in the topic of indigenous and multicultural education. E-mail: shanhua@mail.ncyu.edu.tw

\section{REFERENCES}

1. Arenas, A., Reyes, I. \& Wyman, L. (2010). When indigenous and modern education collide in the global culture. J. Zajda (ed.), Global pedagogies: Schooling for the future, globalization, comparative education and policy research. (pp. 85-110). Springer Science and Business Media.

2. Aslanbeigui, N., Pressman, S., and Summerfield, G. (2003). Toward gender equity: policies and strategies. International Journal of Politics, Culture and Society, 16(3), 327-330. 
3. Chen, S. H. (2009). From tribes to schools: The cultural capital and identity of the indigenous students in Taiwan. Taipei: Psychological Publisher.

4. Chen, S. H., Yang, C. C., Ho, H. F. and Wang, L. P. (2012). Ethnic identity and career aspiration of the Taiwanese indigenous students in the era of globalization. Asian Social Science, 8(10), 23-28. http://dx.doi.org/10.5539/ass.v8n10p23

5. Geo-JaJa, M. A., Payne, S. J., Hallam, P. R., and Baum, D. R. (2009). Gender equity and women empowerment in Africa: The education and economic globalization nexus. In J. Zajda and K. Freeman (eds.), Race, Ethnicity and Gender in Education. 6, 97-121. http://dx.doi.org/10.1007/978-1-4020-9739-3 6

6. Dei, G. J. S. (2010). Teaching Africa: Towards a transgressive pedagogy (explorations of educational purpose). New York, NY: Springer. http://dx.doi.org/10.1007/978-1-4020-5771-7 .

7. Hong, Z. R. (2004). An investigation of Taiwanese female college students' sexist attitudes. Sex Roles, 51(7/8), 455-467. http://dx.doi.org/10.1023/B:SERS.0000049234.20935.e4

8. Hong, Z. R., Veach, P. M., and Lawrenz, F. (2003). An investigation of the gender stereotyped thinking of Taiwanese secondary school boys and girls. Sex Roles, 48(11/12), 495-504. http://dx.doi.org/10.1023/A:1023571111617

9. Raffaelli, M. and Ontai, L. L. (2004). Gender socialization in latino/a families: Results from two retrospective studies. Sex Roles, 50(5/6), 287-299. http://dx.doi.org/10.1023/B:SERS:0000018886.58945.06

10. Richards, P. (2005). The politics of gender, human rights, and being indigenous in Chile. Gender and Society, 19(2), 199-220. http://dx.doi.org/10.1177/0891243204272706

11. Sleeter, C. E., \& Grant, C. A. (1987). An analysis of multicultural education in the United States. Harvard Educational Review, 57(4), 421-444

12. Spradley, J. P. (1979). The ethnographic interview. New York: Harcourt Brace Jovanoich College Publishers.

13. Spradley, J. P. (1980). Participant observation. New York: Holt, Rinehart and Winston.

14. Warren, E., Cooper, T. J. \&Baturo, A. R. (2009). Bridging the educational gap: Indigenous and non-indigenous beliefs, attitudes and practices in a remote Australian school. In J. Zajda\& K. Freeman (2009)(eds.), Race, Ethnicity and Gender in Education. (pp. 213-226). Springer Science and Business Media.

15. Wu, Y. L. (2012). Examining the occupational aspirations of Taiwanese aboriginal adolescents based on the developmental-contextual model of career development. Asia Pacific Education Review, 13, 757-769. http://dx.doi.org/10.1007/s12564-012-9234-9

16. Yen, S. H. (2009). Effective strategies for teaching Taiwanese minority students with low achievement and low socio-economic backgrounds. Asia Pacific Education Review, 10, 455-463.

http://dx.doi.org/10.1007/s12564-009-9053-9 